(C) 2016. This manuscript version is made available under the CC-BY-NC-ND 4.0 license

http://creativecommons.org/licenses/by-nc-nd/4.0/

\title{
Exposure to ozone reduces postharvest quality loss in red and green chilli peppers
}

\author{
Marcin Glowacz*, Deborah Rees \\ Natural Resources Institute, University of Greenwich, Chatham, ME4 4TB, United Kingdom \\ *Corresponding author. Tel.: +44 (0) 1634883564 \\ E-mail address: M.M.Glowacz@greenwich.ac.uk \\ ABSTRACT
}

The effect of continuous exposure to ozone at $0.45,0.9$ and $2 \mu \mathrm{mol} \mathrm{mol}^{-1}$ on quality changes during the storage of red and green chilli peppers at $10{ }^{\circ} \mathrm{C}$ was investigated. Ozone at 0.45 and $0.9 \mu \mathrm{mol} \mathrm{mol}^{-1}$ reduced disease incidence in red peppers, with no further benefits at $2 \mu \mathrm{mol} \mathrm{mol}^{-1}$. Ozone at $0.9 \mu \mathrm{mol} \mathrm{mol}^{-1}$ reduced weight loss during storage and improved firmness maintenance. Skin colour was bleached in red peppers exposed to ozone at $2 \mu \mathrm{mol} \mathrm{mol}{ }^{-1}$, and in green ones at all tested doses. Total phenolic content was not affected by ozone but antioxidant activity was reduced in green chilli peppers exposed to ozone at $2 \mu \mathrm{mol} \mathrm{mol}^{-1}$, due to lower ascorbic acid content in those samples. Ozone at $0.9 \mu \mathrm{mol} \mathrm{mol}^{-1}$ extended the shelf-life of chilli peppers.

Keywords:

Fresh produce

Microbial contamination

Firmness

Visual quality

Antioxidants

\section{Introduction}

Chilli peppers' shelf life is limited by both, contamination with microorganism, including human pathogens, e.g. Escherichia coli (Cerna-Cortes et al., 2012) and visual and textural quality loss (Nunes, Emond, Rauth, Dea, \& Chau, 2009). Chlorine is the most common sanitiser used in the fresh produce industry (Gil, Selma, Lopez-Galvez, \& Allende, 2009); however, there is increasing concern about chlorine being overused and its real efficacy during storage. Thus, the advantages and limitations of numerous alternative methods, e.g. the use of hydrogen peroxide, organic acids, and UV radiation have been reviewed (Ramos, Miller, Brandao, Teixeira, \& Silva, 2013).

The interest in using ozone as a postharvest treatment of fruit and vegetables has recently increased (Miller, Silva, \& Brandao, 2013; Horvitz \& Cantalejo, 2014; Glowacz, Colgan, \& Rees, 2015a) due to its 
(C) 2016. This manuscript version is made available under the CC-BY-NC-ND 4.0 license http://creativecommons.org/licenses/by-nc-nd/4.0/

potential to reduce microbial contamination of the produce, without any chemical residues being left (Khadre, Yousef, \& Kim, 2001), and having no adverse effect on the product's quality, if used at the proper dose.

A number of authors (Ketteringham, Gausseres, James, \& James, 2006; Alexandre, Santos-Pedro, Brandao, \& Silva, 2011; Horvitz \& Cantalejo, 2012; Alexopoulos et al., 2013; Glowacz, Colgan, \& Rees, 2015b) studied the efficacy of ozone in reducing microbial counts on bell peppers, and a few (Horvitz \& Cantalejo, 2010a, b, 2012; Glowacz, Colgan, \& Rees, 2015b) also assessed its effect on physicochemical properties. However, the information on the effects of ozone treatment on the postharvest quality of chilli peppers is scarce (Chitravathi, Chauhan, Raju, \& Madhukar, 2015) and requires further investigation.

Microbial counts were found to be reduced on fresh-cut red bell peppers treated with gaseous ozone at $0.7 \mu \mathrm{mol} \mathrm{mol} \mathrm{l}^{-1}$ for 1-5 minutes prior to storage (Horvitz \& Cantalejo, 2010b, 2012) and on whole red bell peppers continuously exposed to ozone at 0.1 and $0.3 \mu \mathrm{mol} \mathrm{mol}^{-1}$ (Glowacz, Colgan, \& Rees, 2015b) during a 14-day storage period and with a more pronounced effect at the higher dose.

The efficacy of aqueous ozone in reducing microbial loads on fresh-cut red (Alexandre, Santos-Pedro, Brandao, \& Silva, 2011) and whole green (Alexopoulos et al., 2013) bell peppers was found to increase with increasing dose of ozone. However, Ketteringham, Gausseres, James, and James (2006) and Horvitz and Cantalejo (2010a) did not find positive effects of aqueous ozone treatment of fresh-cut peppers. Cut surfaces promote leaching of organic matter that reacts with ozone, thereby reducing its efficiency as an antimicrobial agent. Thus, it has been suggested to treat whole rather than pre-cut peppers.

In a recent study (Chitravathi, Chauhan, Raju, \& Madhukar, 2015), aqueous ozone treatment at 30 $\mu \mathrm{mol} \mathrm{mol}{ }^{-1}$ for 10 min prior to storage reduced microbial counts on chilli peppers during subsequent storage at 8 ${ }^{\circ} \mathrm{C}$. However, and to the best of our knowledge, there is no information in the literature on the effects of continuous exposure to gaseous ozone on the postharvest quality of chilli peppers. In the previous study (Glowacz, Colgan, \& Rees, 2015b) no signs of rotting were observed in bell peppers continuously exposed to ozone at $0.3 \mu \mathrm{mol} \mathrm{mol}{ }^{-1}$, while the growth of fungi on the stem and peduncle was observed in $8.3 \%$ and $25 \%$ of the fruit continuously exposed to ozone at $0.1 \mu \mathrm{mol} \mathrm{mol}^{-1}$ and untreated control, respectively. The objective of this study was to investigate the effects of continuous exposure to ozone at $0.45,0.9$ and $2 \mu \mathrm{mol} \mathrm{mol}{ }^{-1}$ on disease incidence and the physicochemical characteristics of red and green chilli peppers. 
(C) 2016. This manuscript version is made available under the CC-BY-NC-ND 4.0 license

http://creativecommons.org/licenses/by-nc-nd/4.0/

1

2

3

4

5

6

7

8

9

10

11

12

13

14

15

16

17

18

19

20

21

22

\section{Materials and methods}

\subsection{Plant material and handling}

Free from visible defects red and green chilli peppers (Capsicum annuum L.), varieties Serenade and Jalapeno, respectively, were supplied by Barfoots of Botley Ltd, West Sussex, UK.

Experiment design and ozone fumigation system set up was previously described by Glowacz, Colgan, and Rees (2015b). Fruit were kept at $10 \pm 1^{\circ} \mathrm{C}$, and continuously exposed to ozone at approximately $0.45 \pm 0.10$, $0.9 \pm 0.10$ and $2 \pm 0.20 \mu \mathrm{mol} \mathrm{mol}^{-1}$, using FPTU ozone generators (Onnic International, UK). Control chilli peppers were stored under air. Air was circulated to ensure even distribution of ozone and gas concentration was monitored periodically, on the sampling day before taking the produce out from the containers for subsequent assessment, with an L-106 Ozone Monitor (2B Technologies, US). Relative humidity inside the containers was maintained at $90 \pm 3 \%$ and monitored using humidity loggers (Lascar Electronics Ltd, UK). Produce quality, i.e. weight loss, visual quality (signs of rotting, shrivelling, stem browning, skin colour), firmness, content of sugars, bioactive compounds and antioxidant activity, was assessed on arrival and after 7, 10 and 14 days of storage.

\subsection{Measurements}

2.2.1. Weight loss

Weight loss (\%) was determined by comparing the weight of the fruit on the sampling day with their initial weight determined on day 0 .

\subsubsection{Visual quality and firmness}

Rotting, shrivelling and stem browning were recorded as a score ( 0 or $1-$ no/signs of rotting, shrivelling and stem browning, respectively). The number of fruit with defects was recorded and calculated as \% of the assessed sample population (30 chilli peppers from each replicate). Skin colour and fruit firmness were determined using a Minolta CR-400 chroma meter (Minolta, Japan) and a TA.XT plus Texture Analyser (Stable Micro Systems, UK), respectively, as previously described (Glowacz, Colgan, \& Rees, 2015b).

\subsubsection{Biochemical analyses}

Sugars, ascorbic acid (AsA) and total phenolic content were measured by methods given in Glowacz, Colgan, and Rees (2015b), whereas antioxidant activity FRAP (ferric reducing antioxidant power) and the ability of fruit extracts to scavenge DPPH (2,2-diphenyl-1-picrylhydrazyl) free radicals was determined using the method previously described by Ali, Ong, and Forney (2014). 
(C) 2016. This manuscript version is made available under the CC-BY-NC-ND 4.0 license http://creativecommons.org/licenses/by-nc-nd/4.0/

\subsection{Statistical analyses}

Chilli peppers were organised in 6 replicates of 90 peppers, for each variety. Data are presented as mean values from a fully randomised design. The significance of main effect was established using ANOVA. Tukey's test was used to compare individual treatment values. All statistical analyses were performed using GenStat $17^{\text {th }}$ Edition software (VSN International Ltd, UK).

\section{Results and discussion}

\subsection{Disease incidence}

Red chilli peppers were found to be more prone to rotting, compared to green chilli peppers, in which rots were not observed during the storage period. Signs of rotting (primarily moulds) were observed on red chilli peppers after 7 days of storage on $11.1 \%$ and $2.8 \%$ of the control samples and those exposed to ozone at 0.45 $\mu \mathrm{mol} \mathrm{mol}{ }^{-1}$ whilst no microbial growth was found on those peppers subjected to 0.9 and $2 \mu \mathrm{mol} \mathrm{mol}^{-1}$ gaseous ozone. After 10 days, $16.7 \%$ of the control samples showed signs of rotting, whereas disease incidence was significantly reduced to $4.2 \%$ in chilli peppers exposed to ozone at $0.45,0.9$ and $2 \mu \mathrm{mol} \mathrm{mol}{ }^{-1}$, without any difference between doses. Finally, after 14 days of storage, 25\% of the control samples where rotted, whilst signs of rotting were observed on $8.3,8.3$ and $16.7 \%$ of chilli peppers exposed to ozone at $0.45,0.9$ and $2 \mu \mathrm{mol}$ $\mathrm{mol}^{-1}$, respectively. Disease incidence was substantially reduced at both 0.45 and $0.9 \mu \mathrm{mol} \mathrm{mol}^{-1}$. The highest dose of ozone used, probably led to tissue damage, thus facilitating fungal infection, in this way counteracting the beneficial antimicrobial action of ozone.

Reduced disease incidence in peppers exposed to ozone at 0.45 and $0.9 \mu \mathrm{mol} \mathrm{mol}^{-1}$ is in agreement with the results observed by Glowacz, Colgan, and Rees (2015b) and Horvitz and Cantalejo (2010b, 2012), who observed reduced microbial counts on whole red bell peppers continuously exposed to ozone at 0.1 and 0.3 $\mu$ mol mol${ }^{-1}$ (Glowacz, Colgan, \& Rees, 2015b) and fresh-cut red bell peppers treated with gaseous ozone at 0.7 $\mu \mathrm{mol} \mathrm{mol}{ }^{-1}$ for 1-5 minutes prior to storage (Horvitz \& Cantalejo, 2010b, 2012), respectively. On the other hand, it is also clear that the dose of ozone has to be appropriately adjusted for each commodity (Forney, 2003) to avoid unwanted tissue damage.

3.2. Weight loss, shrivelling and stem browning

Chilli peppers lost weight over the storage period. The weight loss was lower in both red and green chilli peppers exposed to ozone at $0.9 \mu \mathrm{mol} \mathrm{mol}{ }^{-1}$; however, this effect was lost after 14 days in ozone-exposed green chilli peppers (Table 1). 
(C) 2016. This manuscript version is made available under the CC-BY-NC-ND 4.0 license http://creativecommons.org/licenses/by-nc-nd/4.0/

Shrivelling and stem browning are both indicators of reduced quality related to the loss of water. The appearance of signs of shrivelling was delayed in red chilli peppers exposed to ozone at 0.45 and $0.9 \mu \mathrm{mol} \mathrm{mol}{ }^{-}$

${ }^{1}$, while stem browning was significantly reduced only in samples exposed to ozone at $0.9 \mu \mathrm{mol} \mathrm{mol}^{-1}$ up to 10 days of storage (Table 1). Green chilli peppers were more susceptible to shrivelling than red ones. Shrivelling was reduced up to 10 days of storage in green chilli peppers exposed to ozone at $0.9 \mu \mathrm{mol} \mathrm{mol}^{-1}$ (Table 1). Increasing the dose from 0.9 to $2 \mu \mathrm{mol} \mathrm{mol}{ }^{-1}$, enhanced shrivelling, this suggests that the dose of ozone at 2 $\mu \mathrm{mol} \mathrm{mol}{ }^{-1}$ was too high, and reduced visual quality of the produce.

Reduced weight loss has previously been observed in kiwi continuously exposed to ozone at $0.3 \mu \mathrm{mol}$ mol $^{-1}$ for 5 months (Minas et al., 2012), cucumbers and courgettes continuously exposed to ozone at $0.1 \mu \mathrm{mol}$ mol $^{-1}$ for 17 days (Glowacz, Colgan, \& Rees, 2015b) and chilli peppers treated with aqueous ozone at $30 \mu \mathrm{mol}$ mol $^{-1}$ for 10 min (Chitravathi, Chauhan, Raju, \& Madhukar, 2015). Water loss from chilli peppers occurs primarily through the cuticle (Kissinger et al., 2005), thus the amount of water loss during storage could be affected by its thickness and composition (Parsons et al., 2013; Lara, Belge, \& Goulao, 2014). Thick cuticle makes the produce less susceptible to damage by preventing the epidermal tissues from ozone action (Ali et al., 2014). The mechanism of ozone action in chilli peppers may involve its effect, via reactive oxygen species (ROS) (Kangasjarvi, Jaspers, \& Kollist, 2005), on the activity of lipoxygenase (LOX), which could lead to reduced membrane damage and skin surface cracking, and reduced water loss (Lara, Belge, \& Goulao, 2014).

Exposure to ozone at 0.45 and $0.9 \mu \mathrm{mol} \mathrm{mol}{ }^{-1}$ had no relevant impact on colour characteristics of red chilli peppers, while in samples exposed to ozone at $2 \mu \mathrm{mol} \mathrm{mol}^{-1}, a^{*}(33.94 \pm 0.29)$ and $b^{*}(16.65 \pm 0.27)$ values were significantly higher than control samples ( $\left.a^{*} 31.00 \pm 0.35 ; b^{*} 15.92 \pm 0.41\right)$ after 14 days, i.e. chilli peppers were more red/yellow, suggesting colour bleaching by the high dose of ozone. Hue angle, however, was not affected, being in the range of 26-27 for all treatments.

In contrast, exposure to ozone even at the lowest doses of 0.45 and $0.9 \mu \mathrm{mol} \mathrm{mol}^{-1}$ affected the colour of green chilli peppers, i.e. they became brighter/lighter (higher $L^{*}$ value) with ozone treatment, especially after 14 days of storage $\left(L^{*} 35.00 \pm 0.52,36.06 \pm 0.37,36.31 \pm 0.40\right.$, and $36.65 \pm 0.47$ in control samples and those exposed to ozone at $0.45,0.9$ and $2 \mu \mathrm{mol} \mathrm{mol}{ }^{-1}$, respectively), suggesting that characteristic dark green colour could be bleached by ozone, due to accelerated chlorophyll degradation. This was further confirmed by hue angle being significantly reduced from $132.2 \pm 0.6$ in control to $128.6 \pm 0.3,129.4 \pm 0.2,127.8 \pm 0.2$ in chilli 
(C) 2016. This manuscript version is made available under the CC-BY-NC-ND 4.0 license http://creativecommons.org/licenses/by-nc-nd/4.0/

88

89

90

91

92

93

94

95

96

97

98 peppers exposed to ozone at $0.45,0.9$ and $2 \mu \mathrm{mol} \mathrm{mol}^{-1}$. However, these differences were not always visually obvious.

It has previously been reported that continuous exposure to ozone at $0.1-0.3 \mu \mathrm{mol} \mathrm{mol}^{-1}$ had no significant effect on skin colour of red bell peppers (Glowacz, Colgan, \& Rees, 2015b). Similarly, the colour was not affected in minimally processed peppers treated with ozone at $0.7 \mu \mathrm{mol} \mathrm{mol}^{-1}$ for up to 5 min (Horvitz \& Cantalejo, 2012). The findings from this study, however suggest that: i) there is a threshold in the ozone dose, i.e. continuous exposure at above $1 \mu \mathrm{mol} \mathrm{mol}{ }^{-1}$, that would affect colour of red chilli peppers; ii) green chilli peppers are more sensitive to ozone than red ones.

\subsection{Firmness}

Both, green and red chilli peppers showed softening during storage (Table 2). In red chilli peppers firmness was reduced during storage in all treatments, but was less pronounced in samples exposed to ozone, being highest at $0.9 \mu \mathrm{mol} \mathrm{mol}{ }^{-1}$. In the case of green chilli peppers no significant difference was observed between control samples and those exposed to ozone, regardless of the dose used. However, firmness maintenance seemed to be improved in ozone exposed chilli peppers at day 10, i.e. the loss of firmness was reduced/delayed. Improved firmness maintenance in ozone exposed chilli peppers is in agreement with findings previously reported for chilli peppers exposed to ozone at $30 \mu \mathrm{mol} \mathrm{mol}{ }^{-1}$ for 10 min prior to storage at $8{ }^{\circ} \mathrm{C}$ (Chitravathi, Chauhan, Raju, \& Madhukar, 2015).

It has been suggested that in the commodities, where the exposure to ozone can significantly reduce water loss during storage, firmness maintenance would be improved (Glowacz, Colgan, \& Rees, 2015b) and in agreement with this, weight loss was also found to be reduced in ozone exposed chilli peppers (Chitravathi, Chauhan, Raju, \& Madhukar, 2015).

Several studies have already reported better firmness retention in ozone exposed fruit, e.g. in cucumbers and courgettes continuously exposed to ozone at $0.1 \mu \mathrm{mol} \mathrm{mol}^{-1}$ (Glowacz, Colgan, \& Rees, 2015b), in tomatoes cyclically exposed to ozone at $4 \mu \mathrm{mol} \mathrm{mol}^{-1}$ for 30 min every $3 \mathrm{~h}$ (Aguayo, Escalona, \& Artes, 2006), and continuously exposed to ozone at $0.05 \mu \mathrm{mol} \mathrm{mol}^{-1}$ and $1 \mu \mathrm{mol} \mathrm{mol}^{-1}$ (Tzortzakis, Borland, Singleton, \& Barnes, 2007).

3.5. Chemical quality characteristics

\subsubsection{Sugars}

Exposure of red chilli peppers to ozone at $0.9 \mu \mathrm{mol} \mathrm{mol}^{-1}$ led to significantly higher content of fructose compared with control samples (Table 3) while the content of glucose was not affected. At higher dose, i.e. 2 
(C) 2016. This manuscript version is made available under the CC-BY-NC-ND 4.0 license http://creativecommons.org/licenses/by-nc-nd/4.0/

118

119

120

121

122

124

125

126

127

128

$\mu \mathrm{mol} \mathrm{mol}{ }^{-1}$, the content of glucose was reduced which could be associated with increased respiration due to tissue damage - the dose of ozone being too high. On the other hand, except the fact that sugar content increased over the storage period in all treatments (Table 3) possibly due to ripening, there was no clear pattern of response in case of green chilli peppers.

\subsubsection{Ascorbic acid content}

In red chilli peppers the content of AsA was not affected until the end of the storage period, when AsA content was significantly increased in chilli peppers exposed to ozone at 0.9 and $2 \mu \mathrm{mol} \mathrm{mol}^{-1}$ (Table 4). On the other hand, the content of DHA - oxidised form of AsA, was found to be reduced in those samples. The highest content of DHA, which is often considered as an indication of stress was observed in the control samples (Table 4), however care is needed, as DHA can undergo further conversion, e.g. an irreversible hydrolysis to 2,3diketogulonic acid.

In green chilli peppers, no significant differences among the treatments were observed until the end of the storage period (day 14), when AsA content decreased and DHA content increased in peppers exposed to ozone at $2 \mu \mathrm{mol} \mathrm{mol} \mathrm{m}^{-1}$ (Table 5), which suggests that these samples were under excess oxidative stress and nutritional quality was reduced. Exposure to ozone at $2 \mu \mathrm{mol} \mathrm{mol}{ }^{-1}$ probably led to an increase in ROS, which then needed to be scavenged by AsA. Plant cells have the capability to reduce the damage caused by ROS using antioxidant enzymes - superoxide dismutase (SOD), ascorbate peroxidase (APX), glutathione reductase (GR), catalase (CAT) and metabolites, including AsA and glutathione (GSH) - to transform ROS to less toxic compounds, e.g. water, using AsA as an electron donor (Mittler, 2002). In the reaction catalysed by APX, AsA is changed into DHA. The loss of AsA can be reduced when the activity of dehydroascorbate reductase (DHAR), an enzyme responsible for converting DHA to AsA is increased.

Changes in the content of AsA during 10 days of storage are in agreement with results observed by others, where AsA content was not altered in whole tomatoes cyclically exposed to gaseous ozone at $4 \mu \mathrm{mol}$ $\mathrm{mol}^{-1}$ for 30 min every $3 \mathrm{~h}$ (Aguayo, Escalona, \& Artes, 2006) or continuously exposed to ozone at $1 \mu \mathrm{mol} \mathrm{mol}^{-1}$ for 6 days (Tzortzakis, Borland, Singleton, \& Barnes, 2007). Highest AsA: DHA ratio observed in red chilli peppers exposed to ozone at $0.9 \mu \mathrm{mol} \mathrm{mol}{ }^{-1}$ indicates higher efficiency of AsA-GSH cycle, which is responsible for regeneration of AsA and has been suggested to play a role in extending the shelf-life of fresh produce (Shigenaga, Yamauchi, Funamoto, \& Shigyo, 2005). 
(C) 2016. This manuscript version is made available under the CC-BY-NC-ND 4.0 license http://creativecommons.org/licenses/by-nc-nd/4.0/

\subsubsection{Total phenolic content}

There were no significant differences among the treatments in terms of total phenolic content. At the end of the storage period, however, total phenolic content was slightly but not significantly reduced in chilli peppers exposed to ozone at $2 \mu \mathrm{mol} \mathrm{mol}{ }^{-1}$. This finding is in agreement with the results observed by Glowacz, Colgan, and Rees (2015b) who did not observe significant differences between red bell peppers exposed to ozone at 0.1 and $0.3 \mu \mathrm{mol} \mathrm{mol}{ }^{-1}$ and control samples. Tzortzakis, Borland, Singleton, and Barnes (2007) also reported that no significant differences were observed between tomatoes exposed to ozone at $1 \mu \mathrm{mol} \mathrm{mol}{ }^{-1}$ and untreated control. The slight decline in total phenolic content at the end of the storage period could be associated with their oxidation by ozone.

\subsubsection{Antioxidant activity}

Regardless of ozone concentration, antioxidant activity was not affected in red chilli peppers (Table 4). Tzortzakis, Borland, Singleton, and Barnes (2007) also did not observe changes in antioxidant activity in tomatoes exposed to ozone at $1 \mu \mathrm{mol} \mathrm{mol} \mathrm{l}^{-1}$ for 6 days. In contrast, antioxidant activity was found to be significantly reduced after 14 days in green chilli peppers exposed to ozone at $2 \mu \mathrm{mol} \mathrm{mol}{ }^{-1}$ when compared with control samples while it was not affected at 0.45 and $0.9 \mu \mathrm{mol} \mathrm{mol} \mathrm{l}^{-1}$ (Table 5), suggesting that green peppers were more sensitive to ozone treatment. Since total phenolic content was not significantly reduced, the observed change in antioxidant activity could be associated with a decline in ascorbic acid content and/or changes in phenolic composition in those samples, presumably due to oxidative stress.

\section{Conclusion}

Continuous exposure of red chilli peppers to ozone at $0.9 \mu \mathrm{mol} \mathrm{mol}^{-1}$ resulted in significant reduction in disease incidence, reduced weight loss and improved firmness maintenance, while total phenolic content and antioxidant activity were not affected. In green chilli peppers, exposure to ozone at $0.9 \mu \mathrm{mol} \mathrm{mol}^{-1}$ reduced weight loss and shrivelling during storage; firmness maintenance was improved after 10 days of storage. The skin colour was lighter at all tested doses, but the produce was still marketable. The application of ozone at 0.9 $\mu \mathrm{mol} \mathrm{mol}{ }^{-1}$ seems to be a feasible solution for reducing quality loss during the storage of both red and green chilli peppers, being more suitable for red chilli peppers.

\section{Acknowledgements}

We are grateful to Barfoots of Botley Ltd who provided financial support for our research as a part of the Innovate UK project on the use of ozone to extend the storage life of fresh produce. 
(C) 2016. This manuscript version is made available under the CC-BY-NC-ND 4.0 license http://creativecommons.org/licenses/by-nc-nd/4.0/

175

176

177

178

179

180

181

182

183

184

185

186

187

188

189

190

191

192

193

194

195

196

197

198

199

200

201

202

203

204

\section{Conflict of interest}

None

\section{References}

Aguayo, E., Escalona, V. H., \& Artes, F. (2006). Effect of cyclic exposure to ozone gas on physicochemical, sensorial and microbial quality of whole and sliced tomatoes. Postharvest Biology and Technology, 39, 169177.

Alexandre, E. M. C., Santos-Pedro, D. M., Brandao, T. R. S., \& Silva, C. L. M. (2011). Influence of aqueous ozone, blanching and combined treatments on microbial load of red bell peppers, strawberries and watercress. Journal of Food Engineering, 105, 277-282.

Alexopoulos, A., Plessas, S., Ceciu, S., Lazar, V., Mantzourani, I., Voidarou, C., Stavropoulou, E., \& Bezirtzoglou, E. (2013). Evaluation of ozone efficacy on the reduction of microbial population of fresh cut lettuce (Lactuca sativa) and green bell pepper (Capsicum annuum). Food Control, 30, 491-496.

Ali, A., Ong, M. K., \& Forney, C. F. (2014). Effect of ozone pre-conditioning on quality and antioxidant capacity of papaya fruit during ambient storage. Food Chemistry, 142, 19-26.

Allende, A., Selma, M. V., Lopez-Galvez, F., Villaescusa, R., \& Gil, M. I. (2008). Role of commercial sanitizers and washing systems on epiphytic microorganisms and sensory quality of fresh-cut escarole and lettuce. Postharvest Biology and Technology, 49, 155-163.

Artes F., Gomez, P., Aguayo, E., Escalona, V., \& Artes-Hernandez, F. (2009). Sustainable sanitation techniques for keeping quality and safety of fresh-cut plant commodities. Postharvest Biology and Technology, 51, 287296.

Cerna-Cortes, J. F., Gomez-Aldapa, C. A., Rangel-Vargas, E., del Refugio Torres-Vitela, M., Villarruel-Lopez, A., \& Castro-Rosas, J. (2012). Presence of some indicator bacteria and diarrheagenic E. coli pathotypes on jalapeno and serrano peppers from popular markets in Pachuca City, Mexico. Food Microbiology, 32, 444-447. Chitravathi, K., Chauhan, O. P., Raju, P. S., \& Madhukar, N. (2015). Efficacy of aqueous ozone and chlorine in combination with passive modified atmosphere packaging on the postharvest shelf-life extension of green chillies (Capsicum annuum L.). Food and Bioprocess Technology, 8, 1386-1392.

Forney, C. F. (2003). Postharvest response of horticultural products to ozone. In D. M. Hodges (Ed.), Postharvest oxidative stress in horticultural crops (pp. 13-54). New York: Food Products Press.

Gil, M. I., Selma, M. V., Lopez-Galvez, F., \& Allende, A. (2009). Fresh-cut product sanitation and wash water disinfection: problems and solutions. International Journal of Food Microbiology, 134, 37-45. 
(C) 2016. This manuscript version is made available under the CC-BY-NC-ND 4.0 license http://creativecommons.org/licenses/by-nc-nd/4.0/

205

206

207

208

209

210

211

212

213

214

215

216

217

218

219

220

221

222

223

224

225

226

227

228

229

230

231

232

Glowacz, M., Colgan, R. \& Rees, D. (2015a). The use of ozone to extend the shelf-life and improve quality of fresh produce. Journal of the Science of Food and Agriculture, 95, 662-671.

Glowacz, M., Colgan, R., \& Rees, D. (2015b). Influence of continuous exposure to gaseous ozone on the quality of red bell peppers, cucumbers and zucchini. Postharvest Biology and Technology, 99, 1-8.

Harris, L. J., Farber, J. N., Beuchat, L. R., Parish, M. E., Suslow, T. V., Garrett, E. H., \& Busta, F. F. (2003). Outbreaks associated with fresh produce: incidence, growth, and survival of pathogens in fresh and fresh-cut produce. Comprehensive Reviews in Food Science and Food Safety, 2, 78-141.

Horvitz, S., \& Cantalejo, M. J. (2010a). Effects of aqueous ozone on quality of minimally processed red bell pepper. Acta Horticulturae, 858, 329-333.

Horvitz, S., \& Cantalejo, M. J. (2010b). Combined effects of gaseous $\mathrm{O}_{3}$ and modified atmosphere packaging on quality and shelf-life of fresh-cut red bell pepper. Acta Horticulturae, 858, 335-340.

Horvitz, S., \& Cantalejo, M. J. (2012). Effects of ozone and chlorine postharvest treatments on quality of freshcut red bell peppers. International Journal of Food Science and Technology, 47, 1935-1943.

Horvitz, S., \& Cantalejo, M. J. (2014). Application of ozone for the postharvest treatment of fruits and vegetables. Critical Reviews in Food Science and Nutrition, 54, 312-339.

Kangasjarvi, J., Jaspers, P., \& Kollist, H. (2005). Signalling and cell death in ozone-exposed plants. Plant Cell and Environment, 28, 1021-1036.

Ketteringham, L., Gausseres, R., James, S. J., \& James, C. (2006). Application of aqueous ozone for treating pre-cut green peppers (Capsicum annuum L.). Journal of Food Engineering, 76, 104-111.

Khadre, M. A., Yousef, A. E., \& Kim, J. G. (2001). Microbiological aspects of ozone applications in food: a review. Journal of Food Science, 66, 1242-1252.

Kissinger, M., Tuvia-Alkalai, S., Shalom, Y., Fallik, E., Elkind, Y., Jenks, M. A., \& Goodwin, M. S. (2005). Characterization of physiological and biochemical factors associated with postharvest water loss in ripe pepper fruit during storage. Journal of the American Society for Horticultural Science, 130, 735-741.

Lara, I., Belge, B., \& Goulao, L. F. (2014). The fruit cuticle as a modulator of postharvest quality. Postharvest Biology and Technology, 87, 103-112.

Miller, F. A., Silva, C. L. M., \& Brandao, T. R. S. (2013). A review on ozone-based treatments for fruit and vegetables preservation. Food Engineering Reviews, 5, 77-106. 
(C) 2016. This manuscript version is made available under the CC-BY-NC-ND 4.0 license http://creativecommons.org/licenses/by-nc-nd/4.0/

233 Minas, I. S., Tanou, G., Belghazi, M., Job, D., Manganaris, G. A., Molassiotis, A., \& Vasilakakis, M. (2012).

234 Physiological and proteomic approaches to address the active role of ozone in kiwifruit post-harvest ripening.

235 Journal of Experimental Botany, 63, 2449-2464.

236 Mittler, R (2002). Oxidative stress, antioxidants and stress tolerance. Trends in Plant Science, 7, 405-410.

237 Nunes, M. C. N., Emond, J. P., Rauth, M., Dea, S., \& Chau, K. V. (2009). Environmental conditions 238 encountered during typical consumer retail display affect fruit and vegetable quality and waste. Postharvest 239 Biology and Technology, 51, 232-241.

240 Parsons, E. P., Popopvsky, S., Lohrey, G. T., Lu, S., Alkalai-Tuvia, S., Perzelan, Y., Boslan, P., Bebeli, P. J.,

241 Paran, I., Fallik, E., \& Jenks, M. A. (2013). Fruit cuticle lipid composition and water loss in a diverse collection

242 of pepper (Capsicum). Physiologia Plantarum, 149, 160-174.

243 Ramos, B., Miller, F. A., Brandao, T. R. S., \& Silva, C. L. M. (2013). Fresh fruits and vegetables—An overview

244 on applied methodologies to improve its quality and safety Innovative Food Science and Emerging

245 Technologies, 20, 1-15.

246 Shigenaga, T., Yamauchi, N., Funamoto, Y., \& Shigyo, M. (2005). Effects of heat treatment on an ascorbate-

247 glutathione cycle in stored broccoli (Brassica oleracea L.) florets. Postharvest Biology and Technology, 38, $248 \quad 152-159$.

249 Tzortzakis, N., Borland, A., Singleton, I., \& Barnes, J. (2007). Impact of atmospheric ozone-enrichment on quality-related attributes of tomato fruit. Postharvest Biology and Technology, 45, 317-325. 